\title{
Condicionantes políticos e técnicos das transferências voluntárias da União aos municípios brasileiros'
}

\author{
Márcia Miranda Soares \\ Universidade Federal de Minas Gerais/ Departamento de Ciência Política \\ Belo Horizonte / MG - Brasil \\ Bruno Guimarães de Melo \\ Herkenhoff e Prates Consultores \\ Belo Horizonte / MG - Brasil
}

\begin{abstract}
O trabalho analisa as transferências voluntárias da União (TVU), via convênios, para os municípios entre 1995 e 2010. O tema está inserido no debate sobre federalismo fiscal e será discutido no contexto da recentralização fiscal brasileira, a partir de 1994. O objetivo é verificar quais fatores definem a maior ou menor participação dos entes locais no total desses recursos a partir de três dimensões explicativas: a político-partidária, a redistributiva e a técnica. Os resultados encontrados, por meio de análise descritiva e de regressão estatística, apontam que receberam mais recursos de TVU: os municípios cujos prefeitos eram do mesmo partido ou da base aliada do presidente, os que proporcionaram maior votação ao presidente em sua eleição e os que tinham maior receita tributária própria, que foi considerada indicador de riqueza e de capacidade técnica. A conclusão é que as TVU para os municípios não são redistributivas, mas condicionadas por fatores políticos e técnicos.
\end{abstract}

Palavras-chave: federalismo fiscal; municípios; transferências voluntárias da União.

Las condiciones políticas y técnicas de las transferencias voluntarias de la Unión a los municipios brasileños

El presente trabajo analiza las transferencias voluntarias del Gobierno Federal (TVU), por intermedio de convenios, para los municipios entre 1995 y 2010. Esta cuestión se inserta en el debate sobre el federalismo fiscal, siendo discutido en el contexto de la re-centralización fiscal brasileña vigente desde 1994. El objetivo es examinar los factores que determinan la mayor o menor participación de las

DOI: http://dx.doi.org/10.1590/0034-7612138727

(c) (1)

Artigo recebido em 4 ago. 2014 e aceito em 9 mar. 2016.

${ }^{1} \mathrm{O}$ artigo foi elaborado a partir de pesquisa financiada pelo Conselho Nacional de Desenvolvimento Científico e Tecnológico (CNPq). Também contou com a colaboração de Camylla Carolyna Cotta, Jéssica Mára Viana Pereira e Gabriela Silva Nogueira de Araujo, alunas de graduação em Gestão Pública da UFMG. 
entidades locales en los recursos totales mediante tres dimensiones explicativas: político-partidaria, redistributiva y técnica. Los resultados, obtenidos por medio del análisis descriptivo y de regresión estadística, muestran que los municipios que obtuvieron más recursos de las TVU son: aquellos cuyos alcaldes eran del mismo partido o formaban parte de la coalición presidencial, aquellos que proporcionaron la más alta votación al presidente en su elección y aquellos que tenían mayores ingresos fiscales propios, que se consideró indicador de riqueza y capacidad técnica. Finalmente se concluye que las TVU a los municipios no tienen un carácter redistributivo, está influenciada por factores políticos y técnicos.

Palabras clave: federalismo fiscal; municipios; transferencias voluntarias del Gobierno Federal.

Political and technical restrictions on the voluntary financial transfers from Brazil's federal government to its municipalities

This paper analyzes the federal government's voluntary transfers (Transferências Voluntárias da União - TVU) to municipalities under certain revenue-sharing agreements, between 1995 and 2010. This subject is an essential part of the debate over fiscal federalism and will be discussed here in the context of fiscal re-centralization in Brazil, as from 1994. The idea is to determine the factors which defined what proportion of these financial resources was allocated to each local entity, using three explanatory dimensions: that of political-parties, that of redistribution, and that of a technical nature. The results obtained, using descriptive analysis and statistical regression, showed that the main beneficiaries of these voluntary federal government transfers were: those municipalities whose mayors were from the same party or parties allied with the President; those municipalities that gave the President the most votes in the elections and those that had the highest tax revenues of their own, considered a sign of wealth and technical capacity. The conclusion reached was that these voluntary federal government transfers to municipalities were in no way redistributive in nature, but rather governed by political and technical considerations.

Keywords: fiscal federalism; municipalities; voluntary federal government transfers.

\section{Introdução}

O Brasil passou por mudanças substantivas a partir dos anos 1980. Houve o retorno da democracia ao país, o fortalecimento da federação, a estabilização monetária e avanços nas políticas sociais. O federalismo fiscal é uma dimensão importante dessas mudanças, entendido de forma ampla como a distribuição de receitas e gastos públicos entre os entes nacional e subnacionais de governo. Na trajetória recente do país, podem ser caracterizados dois momentos: um de descentralização fiscal, vigente nos anos 1980, e outro de recentralização, a partir de meados dos anos 1990, com a União assumindo um papel crucial na redefinição de receitas e gastos públicos.

O objeto deste trabalho são as transferências voluntárias da União (TVU) aos municípios brasileiros no período de 1995 a 2010, momento de recentralização fiscal e dos dois mandatos presidenciais de Fernando Henrique Cardoso e de Luiz Inácio Lula da Silva. É um período marcado por sucessivas iniciativas da União na recomposição de suas receitas, tendo como principal instrumento as contribuições sociais, na definição e indução de gastos dos 
governos subnacionais em políticas sociais e no estabelecimento de responsabilização fiscal, definindo limites de gastos com pessoal e de endividamento aos entes federados. É também um período de expansão das transferências intergovernamentais (tigs), destacadamente as obrigatórias e as destinadas aos municípios e a programas de saúde, educação e assistência social. Em 2010, conforme Baião (2013), as tigs correspondiam a 64\% das receitas orçamentárias dos municípios brasileiros.

As transferências voluntárias perderam terreno na composição das receitas municipais no processo de redemocratização (Arretche, 2010). No período anterior, autoritário, havia ampla centralização fiscal na União e as transferências funcionavam como importante recurso do Poder Executivo nacional para negociar apoio político nos níveis subnacionais. Com a descentralização fiscal dos anos 1980, os municípios ampliaram sua participação nas receitas públicas via arrecadação própria e, principalmente, via transferências constitucionais. Em contrapartida, a União passou a contar com menos recursos para distribuir discricionariamente. A partir dos anos 1990, a União ampliou suas receitas e passou a privilegiar as transferências vinculadas às políticas sociais, destaque para saúde, educação e assistência social, reguladas por legislação própria (transferências legais fundo a fundo), e as transferências diretas de renda aos cidadãos (Benefícios de Prestação Continuada e Bolsa-Família).

Contudo, as TVU não perderam relevância, elas representam recursos adicionais para os municípios ampliarem sua capacidade de implementar políticas públicas, principalmente para realizarem investimentos. Em um contexto de ajuste fiscal, no qual os entes locais têm baixa capacidade de endividamento e devem priorizar gastos sociais, com vinculação crescente das receitas nessas áreas, sobra pouca margem para os municípios ampliarem seus gastos com outras políticas públicas e as TVU acabam sendo recursos atraentes e cobiçados.

Para a União, as TVU representam importante recurso de poder político nas negociações horizontais e verticais. Nas negociações horizontais, a formação de uma coalizão de governo, composta por partidos que detêm a maioria das cadeiras no Congresso Nacional, passa pela distribuição de cargos em órgãos e entidades do Poder Executivo, e esses serão tanto mais disputados quanto maior for o volume de recursos que dispuserem e, tanto melhor, se forem recursos discricionários, o que aumenta o poder dos ocupantes de privilegiar destinatários e políticas.

No plano vertical, as TVU podem ser utilizadas para fortalecer a capacidade de gastos dos municípios e a escolha dos destinatários pode ser compreendida a partir de três dimensões: a político-partidária, a redistributiva e a de capacidade técnica. A dimensão político-partidária envolveria a busca da União por fortalecer suas bases eleitorais e partidárias, privilegiando no recebimento de TVU os entes locais que deram maior apoio eleitoral ao presidente em exercício, ou beneficiando os prefeitos dos partidos do presidente ou de sua base aliada. A dimensão redistributiva implica priorizar municípios mais pobres, com menor capacidade de gasto público. Por fim, as exigências para celebrar um convênio requerem uma estrutura de captação de recursos que envolve apresentação de projetos, negociações técnicas e gestão de convênios, o que pode favorecer os mais capacitados tecnicamente, e os municípios mais ricos podem ser mais eficientes nesse quesito. 
O artigo está situado no campo de estudo do federalismo fiscal e tem como objetivo principal explicar como aquelas três dimensões operam na distribuição de TVU para os municípios brasileiros. Os municípios alinhados partidariamente com o governo central, com prefeito do mesmo partido que o presidente ou de partidos da base aliada ao governo, serão preferidos? Os municípios que proveram maior apoio eleitoral ao presidente em exercício, em sua última eleição, serão beneficiados? E com relação aos entes locais mais pobres, carentes de recursos, a TVU pode ser um mecanismo de dotá-los de maior capacidade para implementar políticas públicas de interesse nacional? Diversamente, municípios que têm mais recursos e podem contar com um corpo técnico mais qualificado, com maior capacidade para responder às exigências e demandas do governo central para celebração de convênios, podem captar mais recursos de TVU?

Para cumprir o objetivo proposto e responder as perguntas formuladas, o trabalho faz uma análise descritiva e de regressão multivariada. O banco de dados utilizado consiste em um painel no qual cada município apresenta uma série de dados ao longo de um período de 16 anos.

O artigo está estruturado em quatro seções, além desta introdução e das considerações finais. A primeira situa o objeto deste artigo, as TVU para municípios brasileiros, no debate acadêmico sobre federalismo fiscal. A segunda seção analisa a posição dos municípios no federalismo fiscal brasileiro, conformado na Constituição de 1988, e as mudanças ocorridas a partir de meados dos anos 1990. São apresentadas também as principais fontes de recursos locais. A terceira seção apresenta, por meio de estatística descritiva, alguns dados da distribuição de TVU aos municípios no período de 1995 a 2010. A seção quatro está centrada na análise da distribuição de TVU aos municípios a partir do uso do método de regressão multivariada. Busca verificar os efeitos líquidos de uma variável, quando se controlam outras variáveis, o que permite responder as perguntas propostas neste estudo com segurança estatística. Os resultados encontrados apontam componentes políticos e técnicos na definição do destino municipal das TVU. As considerações finais fazem uma síntese e balanço dos achados do trabalho, apontando novas perspectivas de estudos.

\section{Federalismo fiscal e transferências intergovernamentais}

O tema do federalismo fiscal ganhou destaque em meados do século passado com o debate sobre as vantagens da descentralização fiscal nos EUA. O trabalho de Tiebout (1956), seguido de Oates (1972) e Musgrave (1983), defendia que a descentralização fiscal é o caminho para a eficiência econômica no setor público, tornando-o similar ao setor privado no provimento de bens e serviços. A proposição central é que tributos e gastos públicos descentralizados são mais eficientes porque promovem concorrência entre os níveis locais para satisfazer os eleitores-consumidores, que podem destituir pelo voto os líderes que não contemplem seus interesses ou mudar-se para uma localidade que melhor atenda suas preferências por tributos e gastos públicos (votar com os pés). 
Trabalhos posteriores buscaram enfatizar, aperfeiçoar ou questionar os enunciados de Tiebout (1956) e seus adeptos. O fato é que o tema da descentralização fiscal se tornou relevante no debate acadêmico e político, considerado uma dimensão importante das relações intergovernamentais, tanto em países federais como unitários, e com efeitos significativos para a mobilização e a alocação de recursos, para a estabilidade macroeconômica, para a prestação de serviços e para a equidade territorial e social (Litvack et al., 1998).

$\mathrm{O}$ acúmulo na área trouxe alguns aprendizados. Primeiro, que a descentralização fiscal não é algo singular, mas um "fenômeno complexo" com diversas formas e dimensões (Litvack et al., 1998; Treisman, 2006). Segundo, que os efeitos da descentralização dependem de sua configuração, de outras instituições e contextos. Portanto, "as consequências da descentralização são complexas e obscuras. Muitos efeitos observados apontam para diferentes direções, produzindo resultado indeterminado" (Treisman, 2006:5). Por fim, eficiência não é o único e nem o principal objetivo a ser buscado em um desenho de descentralização; tão ou mais importante é a equidade territorial e social, fim mobilizado por uma ampla gama de estudos sobre federalismo fiscal. E uma dimensão fundamental a ser analisada na busca por equidade fiscal são as transferências intergovernamentais (tigs).

As transferências intergovernamentais são defendidas em nome da eficiência e da equalização fiscal. Contrariando Tiebout, autores apontam que a descentralização do poder de tributar e gastar no nível local pode aumentar os custos transacionais e impactar negativamente a capacidade do governo central de promover estabilidade macroeconômica, sendo preferível centralizar a arrecadação e distribuir parte dessa arrecadação às unidades subnacionais. As tigs também podem promover equalização fiscal em uma federação ao possibilitar que subunidades mais pobres, por meio de transferências de outros níveis de governo, tenham recursos suficientes para responder as suas atribuições ou necessidades de gastos - equalização vertical ou diminuição do hiato fiscal - e possam garantir um padrão mínimo de bens e serviços mais equânimes em todo o território nacional - equalização horizontal ou redistribuição regional (Tanzi, 1995; Ahmad e Brosio, 2006; Mendes et al., 2008; Rezende, 2010). Outros objetivos ou motivações importantes para a tigs são os de natureza política, na qual elas podem contribuir para promover coesão nacional ou para angariar apoios ou fortalecer as bases políticas do governo central (Arretche e Rodden, 2004; Soares e Neiva, 2011; Amorim Neto e Simonassi, 2013).

A conjugação de eficiência, equidade e objetivos políticos na definição e implementação das tigs é uma tarefa complexa e permeada de trade-offs. Isso é particularmente válido para o Brasil, país federal e marcado por enormes disparidades regionais e locais. Dessa forma, conhecer a configuração e os efeitos das tigs é uma contribuição importante para o campo de estudo do federalismo fiscal. O presente trabalho se insere nesse campo e tem o objetivo de analisar os efeitos das transferências voluntárias da União aos municípios no período mais atual do federalismo fiscal brasileiro, marcado por maior centralização e coordenação intergovernamental. 


\section{Os municípios no federalismo fiscal brasileiro}

\subsection{Os municípios na reforma tributária constitucional de 1988}

A Constituição de 1988 tinha como objetivo reestruturar o Estado brasileiro em bases democráticas, federativas e redistributivas, em contraste com a experiência ditatorial anterior. $\mathrm{O}$ resultado, no aspecto federativo, foi uma descentralização territorial que favoreceu, sobretudo, os municípios. O município foi alçado à condição de terceiro ente federativo e aumentou de forma expressiva sua participação na distribuição das receitas públicas, conforme tabela 1 .

Tabela 1

Recursos tributários distribuídos aos três níveis de governo (1960-2005)

\begin{tabular}{|cccccccc|}
\hline & \multirow{2}{*}{$\begin{array}{c}\text { Carga Tributária } \\
\text { Bruta } \\
\text { Ano }\end{array}$} & \multicolumn{3}{c}{ Arrecadação direta (\%) } & \multicolumn{3}{c|}{ Receita disponível (\%) } \\
\cline { 3 - 8 } & (\% do PIB) & União & Estados & Municípios & União & Estados & Municípios \\
\hline 1960 & 17,4 & 64,0 & 31,3 & 4,7 & 59,5 & 34,1 & 6,4 \\
1970 & 26,0 & 66,7 & 30,6 & 2,7 & 60,8 & 29,2 & 9,9 \\
1980 & 24,5 & 74,7 & 21,6 & 3,0 & 68,2 & 23,3 & 8,6 \\
1988 & 22,4 & 71,7 & 25,6 & 2,7 & 60,1 & 26,6 & 13,3 \\
1990 & 28,8 & 67,0 & 29,6 & 3,4 & 58,9 & 27,6 & 13,5 \\
1995 & 29,4 & 66,0 & 28,6 & 5,4 & 56,2 & 27,2 & 16,6 \\
2000 & 33,4 & 66,7 & 27,6 & 5,7 & 55,8 & 26,3 & 17,9 \\
2005 & 38,9 & 68,4 & 26,0 & 5,6 & 57,6 & 25,2 & 17,2 \\
\hline
\end{tabular}

Fonte: Oliveira (2007:45 e 50).

O aumento das receitas municipais ocorreu por duas vias. A primeira deu-se por via de novo tributo, o Imposto sobre a Transferência de Bens Imóveis (ITBI), antes de competência estadual, e de ampla autonomia para alterar as alíquotas dos tributos próprios, o que beneficiou principalmente os municípios mais ricos (Oliveira, 2007). A segunda e principal via foi o aumento das transferências constitucionais, no qual se destaca o Fundo de Participação dos Municípios (FPM). Criado pelo Código Tributário Nacional, em 1966, esse fundo é composto por percentuais dos dois maiores impostos arrecadados pela União, o sobre renda e proventos de qualquer natureza (IR) e o sobre produtos industrializados (IPI). Em 1967, o FPM detinha $10 \%$ desses dois impostos, tendo baixado para 5\%, em 1969, e alcançado 16\%, em 1985 . Na Constituição de 1988, a participação do FPM nesses impostos foi definida em 20\%, algo que evoluiu para patamares superiores e deverá alcançar 24,5\% em 2016 (EC 84, de 2014). 
O processo de descentralização rumo aos municípios gerou incongruências. A maior capacidade fiscal dos municípios não foi acompanhada de uma descentralização coordenada de competências sobre as políticas públicas. As políticas sociais foram estabelecidas como competências comuns entre os entes federados e cada qual assumiu tais competências de forma bastante irregular, gerando duplicidades e ausências (Bercovici, 2004; Souza, 2005). A falta de mecanismos de responsabilização fiscal dos entes federados levou ao endividamento crescente de estados e municípios. O aumento expressivo das transferências constitucionais com intenções redistributivas desestimulou o esforço de arrecadação próprio dos entes subnacionais e não garantiu melhor redistribuição de renda entre os cidadãos nacionais, conforme apontam alguns estudiosos (Varsano, 1996; Rezende, 2010). Por fim, as transferências constitucionais incentivaram a criação de 1.016 novos municípios no Brasil na década de 1990, desvirtuando ainda mais os fins redistributivos do FPM.

\subsection{As finanças públicas municipais nos anos 1990}

Os anos 1990 foram marcados pela busca da União em recompor sua capacidade financeira, o que ocorreu por meio de aumentos contínuos na carga tributária, conforme se observa na tabela 1. Na ampliação de tributos, a União privilegiou as contribuições sociais, previstas na Constituição como fonte exclusiva de receita federal, vinculadas a gastos sociais. Outra frente de atuação da União foi limitar a autonomia dos estados e municípios para empreenderem gastos e se endividarem. O ápice desse processo foi a Lei de Responsabilidade Fiscal (Brasil, 2000b), que regulamentou o teto para despesas com pessoal e inibiu a capacidade de endividar dos níveis de governo.

Medidas legislativas impactaram a destinação dos gastos municipais, aumentando a vinculação com políticas sociais. A Constituição de 1988 estabeleceu um patamar mínimo de 25\% das receitas de impostos e transferências dos municípios para gastos com educação. Em 1996, a Emenda Constitucional no 14 criou o Fundo de Manutenção do Ensino Fundamental e Valorização do Magistério (Fundef), que subvinculou 15\% das receitas de impostos e transferências dos municípios com o ensino fundamental. Em 2006, a Emenda Constitucional ํo 53 transformou o Fundef em Fundo de Manutenção e Desenvolvimento da Educação Básica e de Valorização dos Profissionais da Educação (Fundeb), que aumentou para 20\% a obrigatoriedade dos gastos com a educação básica. Na saúde, a Emenda Constitucional no 29 (Brasil, 2000a) fixou um patamar mínimo das receitas municipais para aplicação em saúde, 15\% a partir de 2004. Além das vinculações de receitas municipais para educação e saúde, o governo central induziu maiores gastos em políticas sociais mediante transferências via fundos especiais. Essas transferências são regulamentadas por leis específicas que estabelecem condicionantes para o recebimento dos recursos, o que envolve a adesão dos municípios a políticas formuladas no âmbito nacional. Os fundos sociais adotam o mecanismo de transferência de um fundo nacional para os fundos municipais, de forma regular e sem a necessidade de convênios e outros instrumentos afins. É o caso do Fundo Nacional de Saúde (FNS), de 1990, cujos recursos são repassados a Fundos Municipais de Saúde (FMS) para o financiamento de programas do Sistema Único de Saúde (SUS). 
O Fundo Nacional de Assistência Social (FNAS), de 1995, repassa recursos aos Fundos Municipais de Assistência Social (FMAS) para financiar programas e ações de assistência social. As medidas adotadas a partir dos anos 1990 tiveram impactos negativos na participação dos estados nas receitas públicas, mas os municípios seguiram em uma trajetória ascendente, conforme se verifica na tabela 1. Contudo, essa trajetória tem uma perspectiva distinta da descentralização dos anos 1980, é mais uma desconcentração de recursos regulada pelo governo central, na qual os governos subnacionais ampliam suas receitas através de transferências intergovernamentais da União para fins específicos, sendo exemplares as transferências fundo a fundo para as políticas sociais de saúde, de educação e de assistência social. Em síntese, a partir dos anos 1990 houve uma crescente intervenção da União na definição dos gastos municipais, o que significou comprometimento crescente de recursos obtidos via transferências intergovernamentais com políticas sociais desenhadas pelo governo federal.

\subsection{As principais fontes de receitas municipais}

A partir das mudanças no federalismo fiscal brasileiro, chega-se à atualidade com um quadro diversificado de fontes de recursos para os municípios, entre as quais se destacam:

1. Recursos tributários próprios (RT): receitas obtidas por meio de impostos, taxas e contribuições de competência exclusiva dos municípios. Compreendem, entre outros, o Imposto sobre Serviços de Qualquer Natureza (ISS), o Imposto sobre a Propriedade Predial e Territorial Urbana (IPTU), o Imposto sobre Transmissão Inter Vivos de Bens e Imóveis e de Direitos Reais a eles relativos (ITBI), a Taxa de Coleta de Lixo, a Taxa de Combate a Incêndios, a Taxa de Conservação e Limpeza Pública e a Contribuição para Custeio do Serviço de Iluminação Pública.

2. Transferências constitucionais (TC): valores repassados de um ente federativo a outro de forma compulsória e por definição constitucional. No Brasil, prevalecem as transferências incondicionais e redistributivas da União, que buscam amenizar as enormes desigualdades existentes no país. Destacam-se nesse universo o Fundo de Participação dos Municípios (FPM) e o Fundo de Manutenção e Desenvolvimento da Educação Básica e de Valorização dos Profissionais da Educação (Fundeb) (STN, 2008). Dos estados, os municípios recebem $25 \%$ do Imposto sobre Circulação de Mercadoria e Serviços (ICMS) e 50\% do Imposto sobre a Propriedade de Veículos Automotores (IPVA), transferências incondicionais e devolutivas, ou seja, que buscam devolver aos municípios parte do que foi arrecadado em suas bases (Prado, 2001; Mendes et al., 2008).

3. Transferências legais (TL): repasses de recursos da União aos municípios regulados por leis específicas que estabelecem quem pode receber e sob quais condições. São duas as modalidades de transferências legais: as incondicionais, que possibilitam aos municípios definir o destino do recurso recebido, é o caso dos royalties do petróleo. A outra modalidade é a das transferências condicionadas a um fim específico, que admitem os repasses automáticos, sem convênios ou instrumentos afins. É o caso do financiamento via Fundo Nacional de Desenvolvimento da Educação para alguns programas da área educacional e os repasses fundo a fundo (Rio Grande do Sul, 2009:8). 
4. Transferências do Sistema Único de Saúde (TSUS): transferências redistributivas da União destinadas ao financiamento de ações e serviços do SUS, "sendo tratadas destacadamente por conta da relevância do assunto e não pelo tipo de transferência". Podem ser realizadas por meio da celebração de convênios, de contratos de repasses e, principalmente, de repasses fundo a fundo. (CGU, 2005:23)

5. Transferências voluntárias da União (TVU): também conhecidas como transferências discricionárias ou negociadas. De acordo com a Lei de Responsabilidade Fiscal, elas podem ser definidas como "a entrega de recursos correntes ou de capital a outro ente da Federação, a título de cooperação, auxílio ou assistência financeira, que não decorra de determinação constitucional, legal ou os destinados ao Sistema Único de Saúde" (Brasil, 2000a).

Os recursos de transferências voluntárias são repassados aos municípios, predominante, por meio de convênios e contratos de repasse. O convênio é um instrumento jurídico celebrado entre as partes e disciplina a transferência de recursos para a execução de uma política pública de interesse recíproco, com duração definida e em regime de mútua cooperação, o que envolve contrapartida financeira e corresponsabilidade na aplicação e fiscalização dos recursos. O contrato de repasse é instrumento similar, diferenciando-se por envolver a intermediação de instituições ou agências financeiras oficiais federais nas transferências dos recursos, tendo destaque a Caixa Econômica Federal (CGU, 2005).

As cinco fontes de recursos municipais buscam conciliar autonomia fiscal e caráter redistributivo. Os recursos tributários e as transferências devolutivas, como a cota-parte do ICMS, reproduzem as desigualdades econômicas, beneficiando os municípios mais ricos. As transferências constitucionais do FPM apresentam intenção redistributiva, buscando promover maior equidade fiscal. As transferências legais, em sua maioria, e as do SUS apresentam caráter redistributivo, mas não têm valores precisos e estão vinculadas a políticas públicas definidas no âmbito nacional. As receitas de transferências voluntárias da União estão sob o controle principalmente do Executivo nacional, que tem ampla autonomia para definir o volume desses recursos e quais destinatários e políticas beneficiarão. Assim, é desconhecido o caráter dessas transferências, se mais ou menos redistributivo, algo que este trabalho buscará responder. Na composição da receita orçamentária dos municípios brasileiros, conforme dados de Baião (2013:23) para 2010, as receitas de arrecadação tributária corresponderam a 20\%; as transferências intergovernamentais a 64\% e outras fontes, como atividades econômicas do governo, a 16\%. Entre as tigs, prevalecem a cota-parte do ICMS (26\%), o Fundeb (21\%), a cota-parte do FPM (20\%) e as transferências do SUS (13\%). As TVU via convênios respondem por 6\% das receitas municipais. A conclusão é que as TVU representam uma parcela menor das receitas dos municípios. Contudo, elas não são desprezíveis e são atrativas porque aumentam a capacidade municipal de implementar políticas públicas, principalmente as de investimentos, em um contexto marcado pela rigidez orçamentária, na qual se sobressai a alta vinculação com políticas sociais. Também é uma importante fonte de poder para o Executivo nacional, nas suas relações com o Legislativo e com os governos subnacionais. É sob essa ótica que cabe indagar quais critérios são utilizados pela União na distribuição de TVU aos municípios: político-partidários, redistributivos ou técnicos? 


\section{A distribuição de transferências voluntárias da União aos municípios (1995-2010)}

As análises empreendidas nesta e na próxima seção são resultados de um banco de dados construído a partir de informações de convênios disponibilizadas no Portal Transparência, da Controladoria-Geral da União (CGU, 2012). Com isso, não são tratadas as transferências voluntárias efetivadas por meio de contratos de repasses e outros instrumentos. Para melhor delinear o objeto de estudo, as TVU, foram excluídos da base de dados todos os convênios do Ministério da Saúde, em grande parte associados à implementação do Sistema Único de Saúde. ${ }^{2}$ Nos 16 anos considerados, foram 203.447 convênios celebrados com 5.552 municípios, média anual de 12.715 convênios, que totalizaram o valor de 75,8 bilhões de reais, uma média de 4,7 bilhões ao ano, em valores deflacionados para julho de 2010 . No gráfico 1 , ao visualizar a distribuição de TVU pelos agentes receptores, verifica-se que os municípios ampliaram sua participação nas TVU ao longo do período, principalmente a partir de 2003, com o governo Lula, equiparando-se aos governos estaduais.

\section{Gráfico 1}

\section{Distribuição de TVU por agente receptor (1995-2010)}

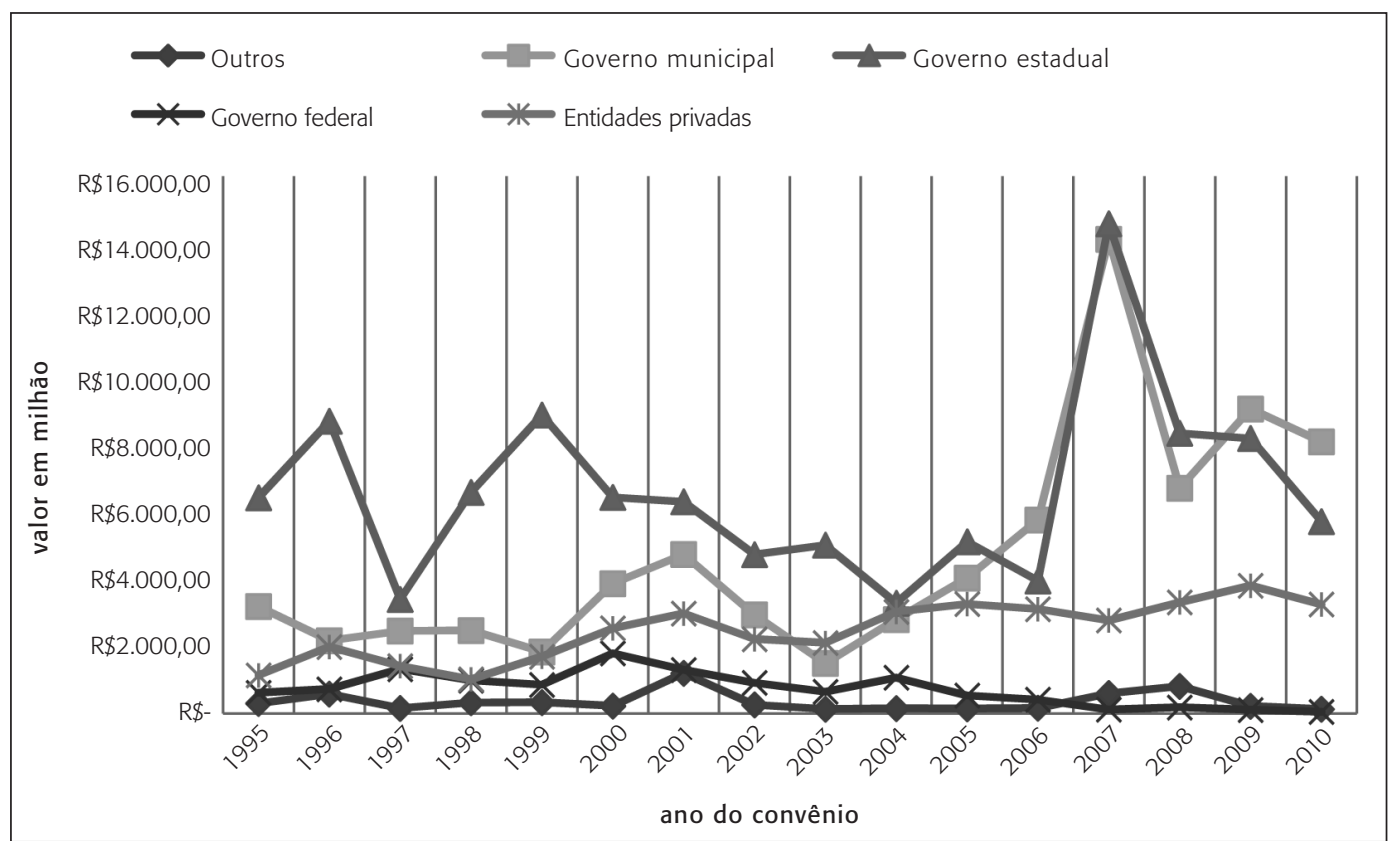

Fonte: Soares e Melo (2012). Valores deflacionados para julho de 2010.

\footnotetext{
${ }^{2}$ Os valores de TVU distribuídos aos municípios se referem a valores empenhados no Orçamento Geral da União. O empenho corresponde à primeira fase de execução de uma despesa e vincula os recursos orçamentários do Tesouro ao gasto correspondente. Na sequência, há a liquidação e o pagamento. Optou-se por trabalhar com o empenho porque os convênios podem se estender por anos, com liberações parciais de recursos, algo que dificultaria a análise.
} 
No universo dos convênios com municípios, as 26 capitais estaduais celebraram 6.135 convênios, total de 13,9 bilhões de reais, o que corresponde a uma média de 538,3 milhões de reais por capital para o período de 16 anos. No interior, foram 5.526 municípios que celebraram 197.312 convênios, total de 62 bilhões, o que equivale a uma média de 11,2 milhões de reais por município, em todo o período. Os dados apontam uma concentração grande de recursos de TVU nas capitais, algo esperado, dadas a maior demanda de infraestrutura e a concentração populacional nesses municípios. Também pode ser resultado da melhor capacidade técnica desses municípios para captar esse tipo de recurso.

Em relação à distribuição por região e por perfil socioeconômico, a tabela 2 aponta que os municípios do Nordeste, Sudeste e Sul foram os que mais celebraram convênios e que mais receberam recursos de TVU. Contudo, ponderando o valor recebido pela população das regiões, observa-se que foram os habitantes dos municípios do Norte, Centro-Oeste e Nordeste os mais beneficiados. A tabela 3 mostra que municípios com menor população tendem a apresentar menor renda e arrecadação tributária per capita, e maior volume de transferências voluntárias da União per capita (TVU). As duas tabelas parecem indicar que as TVU podem ter caráter redistributivo. No entanto, verifica-se que a região Centro-Oeste recebeu mais recursos que o Nordeste, apesar de ter maior renda per capita. Os municípios situados nas duas menores faixas populacionais são os mais beneficiados com TVU, mas eles não são os de menor renda e receita tributária per capita. Também a faixa populacional entre 100 e 500 mil habitantes é mais bem beneficiada por TVU do que a faixa entre 50 e 100 mil, essa última apresentando menor renda per capita. É fato que as capitais recebem mais recursos de TVU, o que aponta para uma perspectiva não redistributiva. Isso é relativizado pelas tabelas 2 e 3 , que apontam que as TVU podem sim beneficiar mais municípios pequenos e de menor renda per capita. Mas há incongruências na relação menor renda per capita e maior TVU, o que deixa em aberto o sentido dessa relação que será examinada na próxima seção.

Tabela 2

Distribuição de TVU per capita aos municípios, por região (média anual, 1995-2010)

\begin{tabular}{|lcccc|}
\hline \multirow{2}{*}{ Região } & № de Convênios & Valor de TVU & População* & TVU per capita \\
\cline { 2 - 5 } & (média anual) & (média anual) & (média anual) & (média anual) \\
\hline Norte & 19.440 & $\mathrm{R} \$ 596.569 .030,04$ & $11.757 .775,19$ & $\mathrm{R} \$ 50,74$ \\
Centro-Oeste & 19.174 & $\mathrm{R} \$ 515.625 .153,69$ & $10.475 .291,38$ & $\mathrm{R} \$ 49,22$ \\
Nordeste & 64.112 & $\mathrm{R} \$ 1.539 .904 .287,38$ & $41.933 .359,50$ & $\mathrm{R} \$ 36,72$ \\
Sul & 49.358 & $\mathrm{R} \$ 664.483 .953,91$ & $23.386 .406,50$ & $\mathrm{R} \$ 28,41$ \\
Sudeste & 51.363 & $\mathrm{R} \$ 1.419 .378 .168,69$ & $65.460 .809,56$ & $\mathrm{R} \$ 21,68$ \\
Brasil & 203.447 & $\mathrm{R} \$ 4.735 .960 .590,75$ & $153.013 .642,13$ & $\mathrm{R} \$ 30,95$ \\
\hline
\end{tabular}

Fonte: Banco de Dados TVU, UFMG, 2012.

*Média anual da população municipal contemplada por TVU no período. Fonte: IBGE (2010). 
Tabela 3

Distribuição de TVU per capita, por perfil socioeconômico dos municípios

(1995-2010)

\begin{tabular}{|lccc|}
\hline \multicolumn{1}{|c}{ Número de Habitantes } & $\begin{array}{c}\text { PIB per capita } \\
\text { (em mil) }\end{array}$ & $\begin{array}{c}\text { Receita Tributária } \\
\text { per capita }\end{array}$ & TVU per capita \\
Até 5.000 & $\mathrm{R} \$ 14.198,82$ & $\mathrm{R} \$ 48,58$ & $\mathrm{R} \$ 93,68$ \\
De 5.001 a 10.000 & $\mathrm{R} \$ 12.750,00$ & $\mathrm{R} \$ 44,10$ & $\mathrm{R} \$ 62,32$ \\
De 10.001 a 20.000 & $\mathrm{R} \$ 11.936,23$ & $\mathrm{R} \$ 43,95$ & $\mathrm{R} \$ 47,38$ \\
De 20.001 a 50.000 & $\mathrm{R} \$ 13.365,60$ & $\mathrm{R} \$ 62,04$ & $\mathrm{R} \$ 33,18$ \\
De 50.001 a 100.000 & $\mathrm{R} \$ 17.643,53$ & $\mathrm{R} \$ 87,01$ & $\mathrm{R} \$ 27,12$ \\
De 100.001 a 500.000 & $\mathrm{R} \$ 24.290,21$ & $\mathrm{R} \$ 147,27$ & $\mathrm{R} \$ 29,52$ \\
Acima de 500.000 & $\mathrm{R} \$ 34.678,08$ & $\mathrm{R} \$ 231,54$ & $\mathrm{R} \$ 19,34$ \\
Brasil & $\mathrm{R} \$ 23.189,85$ & $\mathrm{R} \$ 57,73$ & $\mathrm{R} \$ 30,96$ \\
\hline
\end{tabular}

Fonte: Banco de Dados TVU, UFMG, 2012.

No aspecto político, o gráfico 2 apresenta a participação de nove partidos políticos na TVU distribuída aos municípios, diferenciando o governo FHC e o governo Lula. Os nove partidos são aqueles que prevaleceram à frente dos executivos municipais. Vale destacar que o PSDB era o partido do presidente FHC e PMDB, PFL e PP compunham sua coalizão de governo. O PT era o partido do presidente Lula e PMDB, PP, PTB, PDT e PSB participaram de sua base aliada. Os dados indicam que o alinhamento partidário dos prefeitos ao presidente pode repercutir no montante de TVU recebido. É notória a diferença de participação dos municípios governados por PSDB e PT nos governos FHC e Lula. O PMDB, aliado dos dois presidentes e à frente de um maior número de prefeituras, foi o mais beneficiado entre os partidos. O PFL, aliado do governo FHC e oposição ao governo Lula, teve queda significativa de recursos de TVU no governo Lula. PTB e PSB melhoram sua posição nas TVU no governo Lula, do qual eram aliados.

Da perspectiva ministerial, a tabela 4 elenca os órgãos que mais distribuíram recursos de TVU. Esse aspecto é importante porque as TVU respondem a especificidades ministeriais, como o partido do ministro e aspectos associados a políticas públicas conduzidas por cada ministério. O Ministério das Cidades concentrou em torno de um terço dos recursos de TVU, seguido pelo Ministério da Educação, com 16,6\%, e pelo Ministério da Integração Social, com 11\%. Essa participação dos ministérios será marginalmente trabalhada na seção que segue, mas é um aspecto importante que pode ser mais bem explorado em outros trabalhos. 
Gráfico 2

Participação dos partidos na TVU distribuída aos municípios, segundo partido do prefeito

(1995 a 2002 - FHC, 2003 a 2010 - Lula)

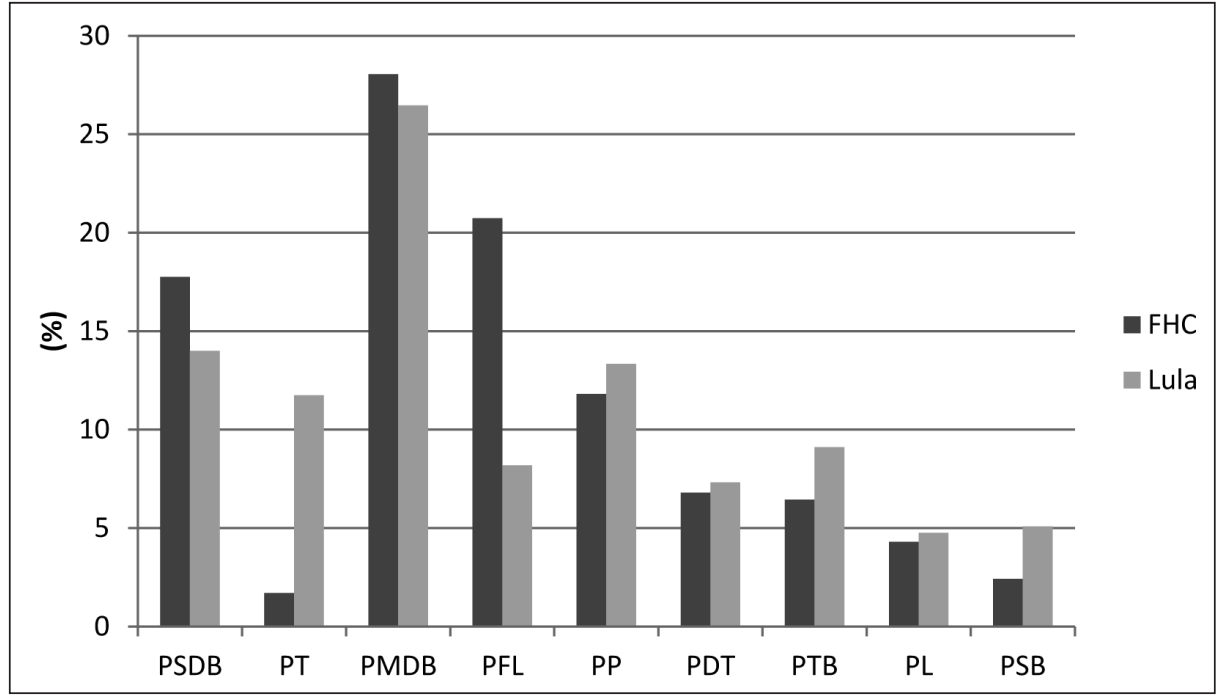

Fonte: Banco de Dados TVU, UFMG, 2012.

Dados partidários obtidos do Tribunal Superior Eleitoral (TSE, 2012).

Tabela 4

Participação dos Ministérios na TVU total distribuída aos municípios, 1995 a 2010

\begin{tabular}{|c|c|}
\hline Ministério & $\begin{array}{l}\text { Participação no Total de } \\
\text { TVU distribuída (\%) }\end{array}$ \\
\hline Ministério das Cidades & 32,9 \\
\hline Ministério da Educação & 16,6 \\
\hline Ministério da Integração Nacional & 11,0 \\
\hline Ministério do Turismo & 9,1 \\
\hline Ministério do Esporte & 5,3 \\
\hline Ministério da Agricultura, Pecuária e Abastecimento & 4,0 \\
\hline Ministério do Desenvolvimento Agrário & 3,9 \\
\hline Ministério do Desenvolvimento Social e Combate à Fome & 3,5 \\
\hline Ministério do Meio Ambiente & 1,7 \\
\hline Ministério da Cultura & 1,0 \\
\hline Total & 88,9 \\
\hline
\end{tabular}

Fonte: Banco de Dados TVU, UFMG, 2012. 
As tabelas e gráficos anteriores apresentam aspectos gerais das TVU e apontam que variáveis políticas e de natureza socioeconômica podem atuar na sua distribuição. A próxima seção utilizará análise de regressão para verificar como os diversos fatores explicativos podem impactar o recebimento de TVU pelos municípios.

\section{Condicionantes políticos, redistributivos e técnicos das TVU aos municípios}

As transferências voluntárias da União (TVU) têm livre destinação e cabe indagar quais têm sido os determinantes na sua distribuição. Três fatores são considerados relevantes na definição do destino municipal dos recursos: os político-partidários, os redistributivos e os relacionados à capacidade técnica dos entes locais para responder as demandas da União na oferta de TVU.

\section{1 Condicionantes político-partidários}

A Constituição de 1988 estabeleceu o planejamento orçamentário como um processo que envolve a produção de três leis: o Plano Plurianual (PPA), a Lei de Diretrizes Orçamentárias (LDO) e a Lei Orçamentária Anual (LOA), de iniciativas privativas do Poder Executivo, sendo submetidas à apreciação e ao emendamento do Poder Legislativo. As TVU são definidas, inicialmente, na elaboração do Projeto de Lei Orçamentária Anual (PLOA) pelo Poder Executivo. Junto a esse Poder, atores políticos diversos apresentam suas demandas de TVU aos municípios. Enviado o PLOA ao Congresso Nacional, novas inclusões de TVU ocorrem por meio das emendas parlamentares.

No processo de execução orçamentária, o Poder Executivo tem liberdade para não efetuar as despesas de TVU, dado que a LOA consiste em uma autorização, e não imposição, para a execução de gastos. E as TVU acabam sendo a parte mais vulnerável das despesas, sendo priorizadas nos contingenciamentos, dado que boa parte do orçamento está comprometida com despesas de pessoal, pagamento de serviços da dívida e transferências constitucionais e legais. Assim, atores políticos diversos precisam continuar barganhando para conseguir efetivar as TVU inseridas no orçamento. Há também brechas na execução do orçamento que possibilitam redefinições de TVU.

Portanto, a definição de TVU para os municípios ocorre na elaboração e execução orçamentária e tem como protagonista o Poder Executivo. Então, é razoável supor que o presidente pode beneficiar os municípios governados por prefeitos do seu partido, no intuito de fortalecer sua base partidária no nível local. Um prefeito que não é do mesmo partido do presidente, mas que é de um partido de sua base aliada, também pode ter mais recursos de TVU, em virtude de seu partido controlar pastas ministeriais.

No plano eleitoral, o apoio do município ao presidente, por ocasião de sua eleição, é um fator a ser considerado, conforme trabalho de Arretche e Rodden (2004), que, ao analisar 
a destinação de TVU para os estados, aponta duas possibilidades. Os municípios que oferecem maior apoio eleitoral ao presidente são privilegiados porque o governo nacional deseja reforçar suas bases eleitorais. Inversamente, municípios podem ser preteridos em benefício de outros que apoiaram menos, se a estratégia do presidente for conquistar votos mediante incentivos financeiros. Pode-se esperar ainda que anos eleitorais tenham comportamento distinto dos demais. Em anos eleitorais para o Executivo nacional, o presidente pode despender mais esforços para fortalecer sua base eleitoral, destinando mais recursos a municípios que concentram seus eleitores. Ou, muito pelo contrário, enviar mais recursos aos municípios que concentram eleitores da oposição, buscando conquistar seus votos. Em anos eleitorais para o executivo municipal, espera-se maior aporte de TVU aos municípios governados por partidos aliados do governo nacional.

\subsection{Condicionantes redistributivos}

Um dos principais objetivos das transferências intergovernamentais é promover maior equalização fiscal entre as unidades territoriais, dotando os entes com menor poder de arrecadação tributária de recursos suplementares (Tanzi, 1995; Ahmad e Brosio, 2006; Prado, 2001; Mendes et al., 2008; Rezende, 2010). Isso pode diminuir as desigualdades territoriais; garantir que os entes federados consigam cumprir suas atribuições governamentais; propiciar um padrão mínimo de bem-estar social a todos os cidadãos nacionais, independentemente da localização; e proporcionar maior estabilidade política, mantendo a atratividade da federação para os mais pobres, já que os mais ricos se beneficiam do mercado comum e tendem a ter maior influência política no âmbito nacional (May, 1969:56).

A Constituição de 1988 promoveu o município à condição de terceiro ente federativo e descentralizou expressivos recursos a seu favor. Para isso, priorizou as transferências fiscais da União, com destaque para o Fundo de Participação dos Municípios. A Constituição, em seu artigo 165, §7으, estabelece ainda que a Lei Orçamentária Anual deve ter "entre suas funções a de reduzir desigualdades inter-regionais, segundo critério populacional". A Lei de Diretrizes Orçamentárias, que orienta a elaboração da LOA, define algumas exigências para as TVU. No período que abrange este trabalho, houve exigência de contrapartida financeira dos municípios, em percentual que considera a população e a localização regional dos mesmos. A LDO 2009, por exemplo, definiu que os municípios teriam como mínimo e máximo de contrapartida: $2 \%$ e $4 \%$, se até 50 mil habitantes; $4 \%$ e $8 \%$, se acima de 50 mil habitantes e localizados nas áreas prioritárias definidas no âmbito da Política Nacional de Desenvolvimento Regional (PNDR), nas áreas da Superintendência do Desenvolvimento do Nordeste (Sudene), da Superintendência do Desenvolvimento da Amazônia (Sudam) e da Superintendência do Desenvolvimento do Centro-Oeste (Sudeco); e 8\% e 40\% para os demais (Brasil, 2009). A contrapartida diferenciada é um incentivo para que os municípios menos populosos e situados nas regiões mais pobres recebam TVU. 
Cumpre verificar se houve caráter redistributivo das TVU. Municípios mais pobres, com menor tributação própria, foram mais beneficiados?

\subsection{Condicionantes técnicos}

A Secretaria do Tesouro Nacional, por meio da Instrução Normativa no 1 (STN, 1997), disciplina a celebração de convênios da União, estabelecendo uma série de requisitos, entre eles a apresentação pelo interessado de plano de trabalho para o objeto proposto, a comprovação de adimplência fiscal, trabalhista e de execução e prestação de contas de convênios anteriores; e a propriedade ou a posse do imóvel objeto de intervenção. No caso de obras, instalações ou serviços, é exigido um projeto básico para caracterizar a intervenção a ser realizada e, algumas vezes, licença ambiental.

Além dessa instrução e outras legislações pertinentes, os ministérios e entidades têm exigências próprias para fazer o repasse dos seus recursos. Criado em 2008, o Sistema de Gestão de Convênios e Contratos de Repasse (Siconv) tornou-se procedimento obrigatório para a celebração e execução de convênios, constituindo-se em mais uma exigência que requer recursos e habilidades técnicas dos municípios. Assim, o processo de captação de recursos de transferências voluntárias é complexo e pode ser caro, quando há exigência de um projeto de engenharia, por exemplo.

Os municípios com menor disponibilidade de recursos financeiros, humanos e tecnológicos podem encontrar dificuldades para atender as exigências para celebrar e executar os convênios e serem preteridos na distribuição de TVU. Uma reclamação recorrente dos órgãos e entidades federais é que os governos subnacionais são ineficientes na apresentação de propostas factíveis e têm dificuldades para executar os convênios celebrados, o que provoca inadimplências e bloqueios no recebimento de novos recursos.

\subsection{Hipóteses e variáveis}

A partir do exposto, as hipóteses de trabalho são que o município recebe mais recursos de transferências voluntárias da União (TVU):

$H_{1}: \rightarrow$ se o partido do prefeito é o mesmo partido do presidente;

$\mathrm{H}_{2}: \rightarrow$ se o partido do prefeito compõe a coalizão do governo nacional;

$H_{3}: \rightarrow$ quanto maior for o percentual de votação obtido pelo presidente no município em sua última eleição;

$H_{4}: \rightarrow$ se for ano de eleição presidencial;

$H_{5}: \rightarrow$ se for ano de eleição municipal;

$H_{6:} \rightarrow$ quanto maior for o percentual de votação obtido pelo presidente no município em sua última eleição e se o ano for de eleição presidencial; ou

$H_{7}: \rightarrow$ se tem menor receita tributária per capita. 
Para testar as hipóteses, foi utilizado o método estatístico de regressão múltipla, que permite identificar a relação causal entre as variáveis que representam cada uma das hipóteses e a variável dependente. Para isso, o método controla os fatores que explicam, ao mesmo tempo, a variável dependente, sob o pressuposto de ceteris paribus. Assim, é possível verificar a influência de cada uma das variáveis explicativas no valor da variável dependente, ao manter constantes os efeitos das outras variáveis. Nesse estudo, a variável dependente é o volume de recursos de TVU per capita recebido pelos municípios em um determinado ano da série temporal analisada, o que corresponde aos valores empenhados dos convênios.

Os dois modelos analíticos adotados têm como variáveis explicativas: 1) uma variável dicotômica (dummy) para verificar se o partido do prefeito é o mesmo do presidente, atribuindo valor "um" para essa condição e "zero" em caso contrário; ${ }^{3}$ 2) outra dummy para verificar se o partido do prefeito é diferente do partido do presidente, mas se pertence a um dos partidos da coalizão do governo federal, codificado como "um" para "sim" e "zero" para "não"; ${ }^{4}$ 3) uma dummy para verificar se o ano é de eleição municipal, codificado como "um" para "sim" e "zero" para "não"; 4) outra dummy para verificar se o ano é de eleição presidencial, codificado como "um" para "sim" e "zero" para "não"; 5) o percentual de votação recebido pelo presidente no município, à época de sua eleição para tal cargo, no primeiro turno; 6) uma variável interativa que utiliza "ano eleitoral para presidente" e "o percentual de votação recebido pelo presidente no município, à época de sua eleição para tal cargo, no primeiro turno"; e 7) receita tributária per capita dos municípios. Os dados de receita tributária municipal própria foram extraídos no portal da Secretaria do Tesouro Nacional (2012). Essa variável será utilizada como proxy de riqueza e capacidade técnica dos governos municipais. Considerou-se que entes mais ricos apresentam melhor estrutura técnica para captar recurso de TVU. Para as variáveis que apresentaram a distribuição de seus valores distante da distribuição normal, foi utilizada a forma funcional logarítmica para permitir a relação linear entre as variáveis dependentes e independentes. Os dados de população utilizados na construção das variáveis per capita foram extraídos do portal do IBGE (2010).

A base de dados foi disposta em séries (uma para cada município) com 16 "ondas" temporais (anos que compõem o período analisado), o que a caracteriza como dados em painel. O fato de que alguns municípios não receberam TVU em todos os anos faz com que o painel seja não balanceado. Devido à configuração dos dados ser transversalmente dominante, o que significa que a quantidade de municípios é bem superior à quantidade de anos, a regressão

\footnotetext{
${ }^{3}$ Considerou-se o partido do prefeito aquele em que ele se elegeu. Os dados eleitorais dessa e das próximas duas variáveis foram obtidos no Tribunal Superior Eleitoral (TSE, 2012).

${ }^{4}$ Os dados de coalizões partidárias nos governos FHC e Lula foram gentilmente cedidos por Octavio Amorim Neto.
} 
utilizada seguiu a metodologia de dados de painel com efeitos fixos. ${ }^{5}$ O método é útil para controlar efeitos não observados e constantes no tempo, que possam estar correlacionados com as variáveis explicativas do modelo estatístico (Wooldridge, 2010; Beck e Katz, 2009).

\subsection{Resultados}

Para analisar os efeitos das variáveis explicativas sobre a TVU recebida pelos municípios, foram utilizados dois modelos similares, conforme tabela 5. A diferença entre eles está na troca da variável que diz se o prefeito é do mesmo partido do presidente da República pela variável que diz se o prefeito não é do partido do presidente, mas pertence a partido da coalizão nacional. A ideia é verificar se o partido do prefeito, diferente do presidente e da base aliada, impacta no recebimento de TVU. Os resultados apontam que municípios receberam mais TVU quando o prefeito era do mesmo partido do presidente. O mesmo aconteceu quando o partido do prefeito não era o mesmo do presidente, mas fazia parte da coalizão de governo nacional. Assim, prefeitos do partido do presidente ou da sua base aliada ganharam mais recursos de TVU do que prefeitos da oposição.

Em ano de eleição municipal, um maior volume de TVU é destinado aos municípios. Isso corrobora a hipótese que supõe uma estratégia do Executivo nacional para fortalecer seus partidários locais no momento em que eles disputam as eleições.

Anos de eleições presidenciais também representam mais recursos de TVU aos cofres públicos locais. O significado desse achado muda quando interagido com o efeito da votação presidencial no município. A contribuição da votação do presidente para angariar mais TVU teve efeitos opostos em anos com e sem eleições presidenciais. Nos anos eleitorais, os municípios que mais votaram no presidente foram preteridos. ${ }^{6}$ A hipótese é que há um esforço do presidente em expandir seu capital político na corrida presidencial nos municípios que menos lhe apoiaram nas últimas eleições, enquanto na maior parte do mandato privilegia aqueles que mais o apoiaram, buscando premiar seu eleitorado. No exame do efeito da variável "proxy" para redistribuição e técnica, a arrecadação tributária própria per capita, observa-se que os municípios mais ricos, com maior arrecadação tributária, foram mais beneficiados com recursos de TVU. A explicação para esse achado parece estar no fato de que municípios mais ricos, como as capitais estaduais, demandam maiores recursos para infraestrutura urbana e têm maior capacidade técnica para captar recursos e executar os convênios.

\footnotetext{
${ }^{5} \mathrm{O}$ teste de Hausman rejeitou a hipótese nula a favor de efeitos aleatórios, ou seja, os efeitos não observados constantes no tempo possuem alguma correlação com as variáveis independentes.

${ }^{6}$ Conforme tabela 5, o retorno em TVU do capital eleitoral em anos não eleitorais foi de $0,7 \%$ a cada $1 \%$ a mais no percentual de votos do município (corresponde ao valor obtido pela variável "votação do presidente no município"). Já o retorno do capital eleitoral em anos eleitorais foi de $-0,2 \%$ a cada $1 \%$ a mais no percentual de votos do município, o que é obtido somando-se o valor da variável "votação do presidente no município" com o valor encontrado na interação.
} 


$$
\text { Tabela } 5
$$

Determinantes do volume de recursos transferidos voluntariamente da União aos governos municipais brasileiros (1995 a 2010)

\begin{tabular}{|c|c|c|}
\hline \multicolumn{3}{|c|}{ Variável dependente: TVU per capita recebida pelos governos municipais, em logaritmo } \\
\hline Variáveis independentes & Modelo 1 & Modelo 2 \\
\hline Prefeito é do partido do presidente & $\begin{array}{l}0.219^{* * *} \\
(0.0202)\end{array}$ & - \\
\hline Prefeito é de partido da coalizão do presidente & - & $\begin{array}{l}0.0235^{*} \\
(0.0139)\end{array}$ \\
\hline Ano eleitoral - prefeito & $\begin{array}{l}0.144 * * * \\
(0.0138)\end{array}$ & $\begin{array}{l}0.148 * * * \\
(0.0145)\end{array}$ \\
\hline Ano eleitoral - presidente & $\begin{array}{l}0.463 * * * \\
(0.0387)\end{array}$ & $\begin{array}{l}0.488 * * * \\
(0.0404)\end{array}$ \\
\hline Votação do presidente no município & $\begin{array}{l}0.00709 * * * \\
(0.000427)\end{array}$ & $\begin{array}{c}0.00778 * * * \\
(0.000451)\end{array}$ \\
\hline Ano eleitoral - presidente* Votação do presidente no município & $\begin{array}{c}-0.00914 * * * \\
(0.000745)\end{array}$ & $\begin{array}{c}-0.00922^{* * *} \\
(0.000784)\end{array}$ \\
\hline Receita tributária per capita do município, log & $\begin{array}{l}0.861^{* * *} \\
(0.00664)\end{array}$ & $\begin{array}{l}0.843^{* * *} \\
(0.00738)\end{array}$ \\
\hline Constante & $\begin{array}{l}-0.582^{* * *} \\
(0.0319)\end{array}$ & $\begin{array}{l}-0.545^{* * *} \\
(0.0358)\end{array}$ \\
\hline N (observações) & 57,008 & 50,138 \\
\hline N (número de municípios) & 5,490 & 5,472 \\
\hline $\mathrm{R}^{2}$ (ajustado) & 0.174 & 0.152 \\
\hline
\end{tabular}

Fonte: Elaboração própria.

Obs. Erro padrão entre parênteses.

*** Significativo a 1\%; ** significativo a 5\%; * significativo a 10\%

\section{Considerações finais}

O artigo buscou apresentar e explicar a distribuição de recursos de transferências voluntárias da União (TVU) aos municípios brasileiros no período de 1995 a 2010, o que compreende os dois mandatos do presidente Fernando Henrique Cardoso e do presidente Luiz Inácio Lula da Silva.

As TVU são marcadas pela discricionariedade e protagonismo do Executivo nacional e são recursos atraentes para os municípios ampliarem seus gastos, em um contexto marcado pelo engessamento orçamentário com despesas correntes e obrigatórias. O trabalho buscou 
verificar se três conjuntos de fatores importavam na destinação desses recursos aos entes locais: políticos, redistributivos e técnicos. Para tal análise, foi construído um banco de dados com valores de TVU destinados aos municípios via convênios, por ano, e com variáveis independentes de caráter político e econômico. Foram estabelecidos dois modelos para análise de regressão.

Os resultados encontrados apontam que fatores políticos interferem na distribuição de TVU aos municípios, e que os entes locais mais beneficiados foram aqueles governados por prefeitos do mesmo partido do presidente ou de partidos da sua base aliada. Em anos de eleição municipal, há um aumento de TVU destinada aos entes locais. Os municípios que ofertaram maiores votações ao presidente na sua última eleição também foram mais bem contemplados com as TVU. Contudo, esse quadro se inverte em anos de eleições presidenciais, quando o Executivo nacional tende a beneficiar os municípios que votaram menos no presidente. Verificou-se também que os municípios mais ricos, com maior receita tributária própria per capita, receberam mais TVU. Esse resultado aponta para um caráter não redistributivo das TVU. O caráter mais político e técnico e menos redistributivo das TVU enfatiza os efeitos pouco redistributivos do sistema de transferências intergovernamentais brasileiro, algo bastante grave em um país marcado por heterogeneidades econômicas. Contudo, as TVU tiveram declínio ao longo do atual período democrático, em função do aumento das transferências constitucionais e legais, que garantem maior autonomia e perenidade fiscal aos municípios e que têm perspectiva redistributiva. Portanto, não parece haver maiores problemas com esse tipo de transferência que privilegia alinhamentos partidários, investimentos urbanos e os mais eficientes na captação e execução dos convênios. O problema das tigs aos municípios reside principalmente no baixo poder redistributivo do Fundo de Participação dos Municípios (Mendes et al., 2008; Rezende, 2010; Baião, 2013).

Como é praxe, vale recomendar novos e mais amplos estudos sobre as tigs brasileiras. No caso das TVU, a dimensão ministerial dessas transferências merece mais investigações. A Emenda Constitucional no $\mathbf{0}$, de 2015, que tornou as emendas parlamentares individuais impositivas, também é algo que instiga novas pesquisas.

\section{Referências}

AHMAD, Ehtisham; BROSIO, Giorgio. Introduction: fiscal federalism - a review of developments in the literature and policy. In: AHMAD, Ehtisham; BROSIO, Giorgio (Ed.). Handbook of fiscal federalism. Cheltenham, UK; Northampton, MA: Edward Elgar Publishing Limited, 2006.

AMORIM NETO, Octavio; SIMONASSI, Andrei G. Bases políticas das transferências intergovernamentais no Brasil (1985-2004). Revista de Economia Política, v. 33, n. 4 (133), p. 704-725, out./ dez. 2013.

ARRETCHE, Marta; RODDEN, Jonathan. Política distributiva na federação: estratégias eleitorais, barganhas legislativas e coalizões de governo. Dados - Revista de Ciências Sociais, Rio de Janeiro, v. 47, n. 3, p. 549-576, 2004. 
BAIÃO, Alexandre L. O papel das transferências intergovernamentais na equalização fiscal dos municípios brasileiros. Dissertação (mestrado) — Fundação Getulio Vargas, Rio de Janeiro, 2013.

BECK, Nathaniel; KATZ, Jonathan N. Modeling dynamics in time-series-cross-section political economy data. Social Science Working Paper 1304. California: California Institute of Technology, 2009. BERCOVICI, Gilberto. Dilemas do Estado federal brasileiro. Porto Alegre: Livraria do Advogado, 2004. BRASIL. Emenda Constitucional no 29, de 13 de setembro de 2000. Altera os arts. 34, 35, 156, 160, 167 e 198 da Constituição Federal e acrescenta artigo ao Ato das Disposições Constitucionais Transitórias, para assegurar os recursos mínimos para o financiamento das ações e serviços públicos de saúde. 2000a. Disponível em: <www.planalto.gov.br/ccivil_03/constituicao/Emendas/Emc/ emc29.htm>. Acesso em: 17 out. 2008.

BRASIL. Lei Complementar no 82, de 27 de março de 1995. Disponível em: <www.planalto.gov. br/ccivil_03/Leis/LCP/Lcp82.htm>. Acesso em: 17 out. 2008.

BRASIL. Lei Complementar no 101, de 4 de maio de 2000 (Lei de Responsabilidade Fiscal — LRF). Estabelece normas de finanças públicas voltadas para a responsabilidade na gestão fiscal e dá outras providências. 2000b. Disponível em: <www.planalto.gov.br/ccivil_03/leis/lcp/lcp101.htm>. Acesso em: 17 out. 2008.

BRASIL. Lei no 12.017, de 12 de agosto de 2009 (LDO 2009). Dispõe sobre as diretrizes para a elaboração e execução da Lei Orçamentária de 2012 e dá outras providências. Disponível em: <www. planalto.gov.br/ccivil_03/_ato2007-2010/2009/Lei/L12017.htm>. Acesso em: 15 ago. 2010.

CGU. Controladoria-Geral da União. Portal da Transparência do Governo Federal. Disponível em: <www.portaltransparencia.gov.br/>. Acessos em: 2010, 2011 e 2012.

CGU. Controladoria-Geral da União. Secretaria Federal de Controle Interno. Gestão de recursos federais: manual para os agentes municipais. Brasília, 2005. Disponível em: <www.cgu.gov.br/ publicacoes/ManualGestaoRecursosFederais/index.asp>. Acesso em: 15 ago. 2010.

IBGE. Instituto Brasileiro de Geografia e Estatística. Departamento de População e Indicadores Sociais. Disponível em: <www.ibge.gov.br/home/estatistica/populacao/projecao_da_populacao/ default.shtm>. Acesso em: 6 jul. 2010.

IPEA. Instituto de Pesquisa Econômica Aplicada. Governo gastador ou transferidor? - um macrodiagnóstico das despesas federais (2001-2011). Comunicados do Ipea, Brasília, n. 122, 2011.

LITVACK, Jennie; AHMAD, Junaid; BIRD, Richard. Rethinking decentralization in developing countries. Sector Studies Series. Washington, DC: The World Bank, 1998.

MAY, Ronald J. Federalism and fiscal adjustment. Oxford: Oxford University Press, 1969.

MENDES, Marcos; MIRANDA, Rogério B.; COSIO, Fernando B. Transferências intergovernamentais no Brasil: diagnóstico e proposta de reforma. Consultoria Legislativa do Senado Federal. Texto para Discussão, Brasília, n. 40, 2008. 
MINISTÉRIO DA EDUCAÇÃO. Fundo Nacional de Desenvolvimento da Educação (FNDE). Disponível em: <www.fnde.gov.br/index.php>. Acesso em: 12 maio 2012.

MPOG. Ministério do Planejamento, Orçamento e Gestão. Portal dos Convênios. Disponível em: <www.convenios.gov.br/portal/index.html>. Acesso em: 18 maio 2012.

MUSGRAVE, Richard A. Who should tax, where, and what. In: MCLURE, Charles (Ed.). Tax assignment in federal countries. Canberra: Centre for Research on Federal Financial Relations, Australian National University, 1983. p. 2-19.

OATES, Wallace. Fiscal federalism. Nova York: Harcourt Brace Jovanovich, 1972.

OLIVEIRA, Fabrício A. Teorias da federação e do federalismo fiscal: o caso brasileiro. Texto para Discussão, Belo Horizonte, n. 43, 2007.

PRADO, Sergio. Transferências fiscais e financiamento municipal no Brasil. São Paulo Ebap; Konrad Adenauer, 2001.

REZENDE, Fernando. Federalismo fiscal: em busca de um novo modelo. In: OLIVEIRA, Romualdo P.; SANTANA, Wagner (Org.). Educação e federalismo no Brasil: combater as desigualdades, garantir a diversidade. Brasília, DF: Unesco, 2010. p. 71-88. Disponível em: < http://unesdoc.unesco.org/ images/0018/001873/187336por.pdf>. Acesso em: 13 fev. 2012.

RIO GRANDE DO SUL. Secretaria do Planejamento e Gestão. Manual de captação de recursos da União. Rio Grande do Sul, 2009. Disponível em: <www2.turismo.rs.gov.br/uploads/12429242200GU_Manual.pdf>. Acesso em: 15 jun. 2009.

STN. Secretaria do Tesouro Nacional. Instrução Normativa STN nº 1, de 15 de janeiro de 1997. Disciplina a celebração de convênios de natureza financeira que tenham por objeto a execução de projetos ou realização de eventos e dá outras providências. Disponível em: <www.stn.fazenda.gov. br/legislacao/download/contabilidade/IN1_97.pdf>. Acesso em: 19 jun. 2012.

STN. Secretaria do Tesouro Nacional. O que você precisa saber sobre as transferências constitucionais relativas aos fundos de participação dos estados e dos municípios. Brasília, 2012. Disponível em: <www.tesouro.fazenda.gov.br/servicos/download/cartFPEeFPM.pdf>. Acesso em: 10 fev. 2012.

STN. Secretaria do Tesouro Nacional. Transferências constitucionais. Brasília, DF, 2008. Disponível em: <www.tesouro.fazenda.gov.br/estados_municipios/transferencias_constitucionais.asp > Acesso em: 11 out. 2008.

SOARES, Márcia M.; MELO, Bruno G. Banco de dados TVU. Belo Horizonte: UFMG, 2012.

SOARES, Márcia M.; NEIVA, Pedro R. P. Federalism and public resources in Brazil: federal discretionary transfers to states. Brazilian Political Science Review - BPSR, v. 5, n. 2, p. 94-116, 2011. Disponível em: <www.bpsr.org.br/index.php/bpsr/article/view/127/118>. Acesso em: 5 fev. 2016.

SOUZA, Celina. Federalismo, desenho constitucional e instituições federativas no Brasil pós-1988. Revista Sociologia e Política [online], n. 24, p. 105-121, 2005. Disponível em: <www.scielo.br/pdf/ rsocp/n24/a08n24.pdf>. Acesso em: 18 fev. 2012. 
TANZI, Vito. Fiscal federalism and descentralization: a review of some efficiency and macroeconomic aspects. In: BRUNO, Michael; PLESKOVIC, Boris (Ed.). Annual World Bank conference on development economics. Washington, DC: The World Bank, 1995.

TIEBOUT, Charles. A pure theory of local expenditures. The Journal of Political Economic, v. 64, n. 5, p. 416-424, 1956.

TREISMAN, Daniel. The architecture of government: rethinking political decentralization. Forthcoming Nova York: Cambridge University Press, out. 2006.

TSE. Tribunal Superior Eleitoral. Eleições. Disponível em: <www.tse.jus.br/@@paginainicial>. Acesso em: 2011 e 2012.

VARSANO, Ricardo. A evolução do sistema tributário brasileiro ao longo do século: anotações e reflexões para futuras reformas. Pesquisa e Planejamento Econômico, Rio de Janeiro, v. 27, n. 1, 1996. Disponível em: <http://ppe.ipea.gov.br/index.php/ppe/article/view/735>. Acesso em: 18 fev. 2012.

WOOLDRIDGE, Jeffrey M. Introdução à econometria: uma abordagem moderna. 4. ed. São Paulo: Cengage Learning, 2010.

Márcia Miranda Soares é doutora em ciência política e professora adjunta do Departamento de Ciência Política da Universidade Federal de Minas Gerais (UFMG). E-mail: marciamsoares@uol.com.br.

Bruno Guimarães de Melo é graduado em gestão pública e consultor em avaliação de políticas públicas da Herkenhoff e Prates Consultores. E-mail: brunoguimelo@gmail.com. 